\title{
CT and MRI findings of cystic renal cell carcinoma: comparison with cystic collecting duct carcinoma
}

\author{
Qingqiang Zhu ${ }^{\dagger}$, Jun Ling ${ }^{\dagger}$, Jing Ye ${ }^{*}$, Wenrong Zhu, Jingtao Wu and Wenxin Chen
}

\begin{abstract}
Background: Cystic renal cell carcinoma (CRCC) and cystic collecting duct carcinoma (CCDC) share similar oncogeni and some imaging findings. The aim of this study was to characterize the clinical and $C T$ imagings features of CRCC and CCDC.
\end{abstract}

Methods: Thirty-three patients with CRCC and thirteen patients with CCDC with pathologically proven were retrospectively studied. Tumor characteristics were assessed.

Results: On CT imaging, 33 patients(100\%) with CRCC and 13 patients(100\%) with CCDC, tumors calcifications (8 vs. $9, P<0.0001$ ), had a clear boundary (capsule sign, 30 vs. $2, P<0.0001$ ), infiltrative appearance ( 1 vs. $13, P<$ $0.0001)$, exogenous appearance ( 29 vs. $3, P<0.0001)$, invaded the renal pelvis or ureter $(1$ vs. $10, P<0.0001)$, hemorrhage (1 vs. $10, P<0.0001)$, had retroperitoneal lymph node or distant metastasis $(2$ vs. $10, P<0.0001)$, thickened enhancing internal septations (31 vs. $2, P<0.0001$ ), and mural soft-tissue nodules ( 21 vs. $1, P<0.0001)$. On MR imaging, 13 patients(39\%) with CRCC and 4 patients(31\%) with CCDC, all CRCCs appeared hypointense on T1weighted images and hyperintense on T2-weighted images, however, all CCDCs appeared hypointense on T1weighted images and hypointense on T2-weighted images $(P<0.0001) .33$ patients with $C R C C$, they were all alive from3 years to 10 years follow-up, however, 13 patients with CCDC, of which 11 patients were able to be followed up, and 9 patients expired within 5 years of the initial diagnosis and the others are currently still alive.

Conclusions: Distinguishing features of CRCC and CCDC included calcifications, capsule signs, infiltrative appearance, metastasis, internal septations, mural nodules and signal on CT or MR images. These imaging features may help in differentiating the two renal tumor types.

Keywords: Cystic renal cell carcinoma, Cystic collecting duct carcinoma, Differential diagnosis, Computerized tomography

\section{Background}

Cystic renal cell carcinoma (CRCC) composed entirely of numerous cysts, the septa of which contain small groups of clear cells indistinguishable from grade I clear cell carcinoma [1]. Collecting duct carcinoma is rare,

\footnotetext{
*Correspondence: yejing197206@163.com

${ }^{+}$Qingqiang Zhu and Jun Ling are both first authors.

Department of Medical Imaging, Clinical Medical College, Yangzhou

University, No 98 West Nantong Road, 225001 Yangzhou, China
}

accounting for $<1 \%$ of renal malignancies, especially for cystic tumors [2]. It is interesting that CRCC and cystic collecting duct carcinoma (CCDC) share similar oncogenic, histologic features and some imaging findings [3]. No instance of progression of CRCC is known and no tumour with these features has ever recurred or metastasized. However, the CCDCs have a poor prognosis with many being metastatic at presentation. About two-thirds of CCDC patients die of their disease within two years

\section{$\mathrm{BMC}$}

(C) The Author(s). 2021 Open Access This article is licensed under a Creative Commons Attribution 4.0 International License, which permits use, sharing, adaptation, distribution and reproduction in any medium or format, as long as you give appropriate credit to the original author(s) and the source, provide a link to the Creative Commons licence, and indicate if changes were made. The images or other third party material in this article are included in the article's Creative Commons licence, unless indicated otherwise in a credit line to the material. If material is not included in the article's Creative Commons licence and your intended use is not permitted by statutory regulation or exceeds the permitted use, you will need to obtain permission directly from the copyright holder. To view a copy of this licence, visit http://creativecommons.org/licenses/by/4.0/ The Creative Commons Public Domain Dedication waiver (http://creativecommons.org/publicdomain/zero/1.0/) applies to the data made available in this article, unless otherwise stated in a credit line to the data. 
of diagnosis [3]. A radical operation might be regarded as an over-treatment for CRCC, with nephron-sparing surgery (partial nephrectomy) being a more appropriate alternative. Nephron-sparing surgery has been recommended for CRCC by many authors, with increasingly many studies confirming good long-term results and excellent patient survival [4]. However, a radical operation is advocated by many surgeons for CCDC. So, an accurate diagnosis is important for guiding clinical treatment. Therefore, the aim of this study was to characterize the clinical and CT imagings features in 33 cases of CRCC and 13 cases of CCDC.

\section{Methods}

\section{Dataset}

This study was approved by our institutional review board with a waiver of the requirement for written informed consent. Exclusive criteria included: (1) patients who received previous treatment or experienced postoperative recurrence of $C D C$; (2) the diameter of the mass in an axial plane less than $1 \mathrm{~cm}$; (3) the mass was solid. A search of pathology records and PACS system identified 33 patients with CRCC and 13 cases of CCDC retrospectively who were hospitalized at our hospital between 2010 and 2020. Details of the patients age, gender, surgery or biopsy confirmation, metastasis, and clinical symptoms were recorded.

\section{CT imaging technique}

CT was performed with one of two clinical scanners: a 16-MDCT scanner, and a 64-MDCT scanner (Lightspeed Ultra; GE Healthcare). Scanning parameters were $120 \mathrm{kVp}$; 200-300mAs; section thickness, $3 \mathrm{~mm}$; collimation, $0.6-2.5 \mathrm{~mm}$; pitch, $1.0-1.4$; reconstruction interval, $50 \%$; FOV, $33 \mathrm{~cm}$; rotation time, $0.5 \mathrm{~s}$; reconstruction kernel, B40. Images were obtained with a renal mass protocol that included unenhanced images followed by nephrographic phase images $120 \mathrm{~s}$ after IV administration of nonionic contrast medium (iohexol $350 \mathrm{mgI} / \mathrm{mL}$, Omnipaque, GE Healthcare) at $3-4 \mathrm{~mL} / \mathrm{s}$ and volume of $1.5 \mathrm{~mL} / \mathrm{kg}$ followed by a $20-\mathrm{mL}$ saline flush.

\section{Magnetic Resonance Imaging (MRI)}

Thirteen cases of CRCC and four cases of CCDC also underwent unenhancement MRI. MRI examinations were performed with a 3.0-T MR scanner (GE 750, Milwaukee, WI, USA) using a 6 channel array body coil and a 24 channel phased array spine coil integrated into the scanner table. All sequences were acquired with anterior and posterior saturation bands. Axial T1-weighted (T1W) and T2-weighted (T2W) MR images were obtained during breath-hold.

\section{Pathologic examination}

The histopathologic criteria included the macroscopic and microscopic aspects of the tumors. We examined microphotographs obtained with HE staining, in order to observe the cellular morphology and growth patterns of the tumors. Gross specimens were evaluated at the time of surgery for fibrous capsule formation, invasion into the renal calyx, pelvis or ureter, and invasion into the renal vein or inferior vena cava. Pathological specimens were observed by light microscopy and immunohistochemical analysis. All renal tumors were confirmed to be CRCC or CCDC.

\section{Imaging analysis and statistics}

Two radiologists with more than 10 years' experience each, blinded to the final diagnosis, reviewed the CT or MR images in consensus at a picture archiving and communication system workstation. Before image interpretation, the readers met and agreed on a scoring system to be used for cyst classification, and they designed a data collection sheet. Readers recorded the Bosniak cyst category in each case [5, 6]. After the independent interpretation sessions, a consensus reading was used for cases of disagreement as to cyst classification. The evaluated parameters included tumor calcifications, hemorrhage, signal, thickened enhancing internal septations and mural soft-tissue nodules. The presence of a capsule, retroperitoneal lymph nodes or other metastasis, perinephric stranding, hydronephrosis, and renal tissue invasion were also documented. Infiltrative growth on CT/MRI is characterized by poorly marginated borders between the tumor and normal renal parenchyma, whereas exogenous growth is characterized by welldefined bulging tumor margins that displace normal parenchyma. Internal septations: one or more complete or partial septations within the mass. Lymph node metastasis was indicated when a lymph node was enlarged more than $1.5 \mathrm{~cm}$ in diameter. Hemorrhage component was considered to be present if unenhanced attenuation > $45 \mathrm{HU}$, non-enhancing was noted during CT enhancement.

Calcification component was considered to be present if unenhanced attenuation $>100 \mathrm{HU}$.

\section{Statistical analysis}

Statistical analyses were undertaken using SPSS 17.0 statistical software (SPSS Inc, Chicago, Illinois, USA). Numeric data were expressed as mean \pm standard deviation and categorical data were expressed as percentages. Independent-samples $t$ test was used to analyze normally distributed continuous data. Evaluated characteristics were compared using fisher's exact test. Interobserver agreement of CT and MRI features was evaluated by using the intra class correlation coefficient (ICC) with 
$95 \%$ confidence interval $(\mathrm{CI})(\leq 0.20$, slight; $0.21-0.40$, fair; $0.41-0.60$, moderate; $0.61-0.80$, substantial; and $0.81-1.00$, perfect). $P<0.05$ was considered statistically significant.

\section{Results}

The clinical and CT or MR imaging features of CRCC and CCDC

The study included 33 patients (20 females and 13 males) with CRCC and 13 patients (7 males and 6 females) with CCDC. The mean age at diagnosis was slightly higher in patients with CRCC (52.1 years; range 43 to 68 years) than in those with CCDC (53.2 years; range 37 to 68 years, $P>0.05$ ). Presenting symptoms of CRCC and CCDC included flank pain (26 vs. $12, P>$ 0.05 ), hematuria (5 vs. $11, P<0.0001$ ), palpable mass (9 vs. $3, P>0.05)$ and fever (12 vs. $5, P>0.05)$.

There was evidence of calcifications in 8 cases of CRCC whereas 9 patients with CCDC had evidence of calcifications $(P<0.0001$, Table 1$)$. In 30 patients with CRCC (Figs. 1 and 2) and in 2 with CCDC (Figs. 3 and 4) the tumors had a clear boundary $(P<0.0001$, Table 1$)$. Tumors showed an infiltrative appearance on CT in 13 cases of CCDC (Figs. 3 and 4), whereas only one case of CRCC showed an infiltrative appearance $(P<0.0001)$. An exogenous appearance was present in 29 of CRCC (Figs. 1 and 2), but an exogenous appearance was present in 3 of CCDC $(P<0.0001$, Table 1$)$. In one patient with CRCC and in 10 with CCDC (Fig. 3 ) the tumors invaded the renal pelvis or ureter $(P<0.0001)$. In 2 patients with CRCC and 10 patients with CCDC (Fig. 4d) had retroperitoneal lymph node or distant metastasis $(P<0.0001)$. Hemorrhage was found in 10 cases with CCDC whereas only one case was found in CRCC $(P<$ 0.0001, Table 1). In 31 patients with CRCC (Figs. 1 and 2) and in 2 with CCDC the tumors had thickened enhancing internal septations $(P<0.0001)$. Mural softtissue nodules were found in 21 cases with CRCC (Fig. 2)

Table 1 Comparative study of CT appearances in cystic renal cell carcinoma ( $n=33$ ) and cystic collecting duct carcinoma ( $n=13)$

\begin{tabular}{llll}
\hline Main CT findings & CRCC $(\boldsymbol{n}=\mathbf{3 3})$ & $\mathbf{C C D C}(\boldsymbol{n}=\mathbf{1 3})$ & $\boldsymbol{P}$ value \\
\hline calcification & 8 & 9 & 0.004 \\
capsule sign & 30 & 2 & $<0.0001$ \\
infiltrative appearance & 1 & 13 & $<0.0001$ \\
exogenous appearance & 29 & 3 & $<0.0001$ \\
invaded renal pelvis/ ureter & 1 & 10 & $<0.0001$ \\
metastasis & 2 & 10 & $<0.0001$ \\
hemorrhage & 1 & 10 & $<0.0001$ \\
internal septations & 31 & 2 & $<0.0001$ \\
mural nodules & 21 & 1 & $<0.0001$ \\
\hline
\end{tabular}

Note: CRCC cystic renal cell carcinoma, CCDC cystic collecting duct carcinoma whereas only one case was found in $\operatorname{CCDC}(P<0.0001$, Table 1).

On MR imaging, 13 patients with CRCC and 4 patients with $\mathrm{CCDC}$, all CRCCs appeared hypointense on T1-weighted images (Fig. 5a) and hyperintense on T2weighted images (Fig. 5b), however, all CCDCs appeared hypointense on T1-weighted images (Fig. 5c) and hypointense on T2-weighted images (Fig. 5d) $(P<$ 0.0001).

\section{Interobserver agreement}

The kappa value for the independent readings of the two radiologists was 0.926 , perfect agreement.

\section{Follow-up}

Thirty-three patients with CRCC underwent total nephrectomy(tumor grading, III/IV, $n=19$ ) or local resectiony(tumor grading, I/II, $n=19$ ) with a satisfactory outcome. No adjuvant therapy was given, and they were all alive without manifesting disease or any other signs or symptoms from 3 years to 10 years follow-up.

In this study, all of the 13 patients with CCDC underwent radical nephrectomy, of which 11 patients were able to be followed up. 9 patients expired within 5 years of the initial diagnosis and the others are currently still alive.

\section{Pathologic findings}

Microscopy sections of CRCC tumor from two different patients are shown in Figs. 1e and 2d. Microscopic analysis indicated that CRCC tumor cells showed the lining cells are flat or plump and their cytoplasm ranges from clear to pale. The septa consist of fibrous tissue, often densely collagenous.

Microscopy sections of CCDC tumor from two different patients are shown in Figs. 3e and 4e. Microscopic analysis indicated that CCDC tumor cells showed tubular, papillary, tubulopapillary, pseudopapillary, and cribriform patterns.

\section{Discussion}

According to the 2004 World Health Organization classification of renal tumors, CRCC is a rare subtype of renal cell carcinoma. There is a male:female predominance of 3:1. All have been adults (age range $20-76$ years, mean $=51$ ). No instance of progression of CRCC is known [7].

Completely CCDCs are rare, accounting for $<1 \%$ of renal malignancies. Over 100 cases have been described and there is a wide age range from 13 to 83 years (mean, about 55) with a male to female ratio of 2:1 [8]. It is interesting that CRCC and CCDC share similar oncogenic, histologic features and some imaging findings. Although CRCC and CCDC have been relatively well described in 


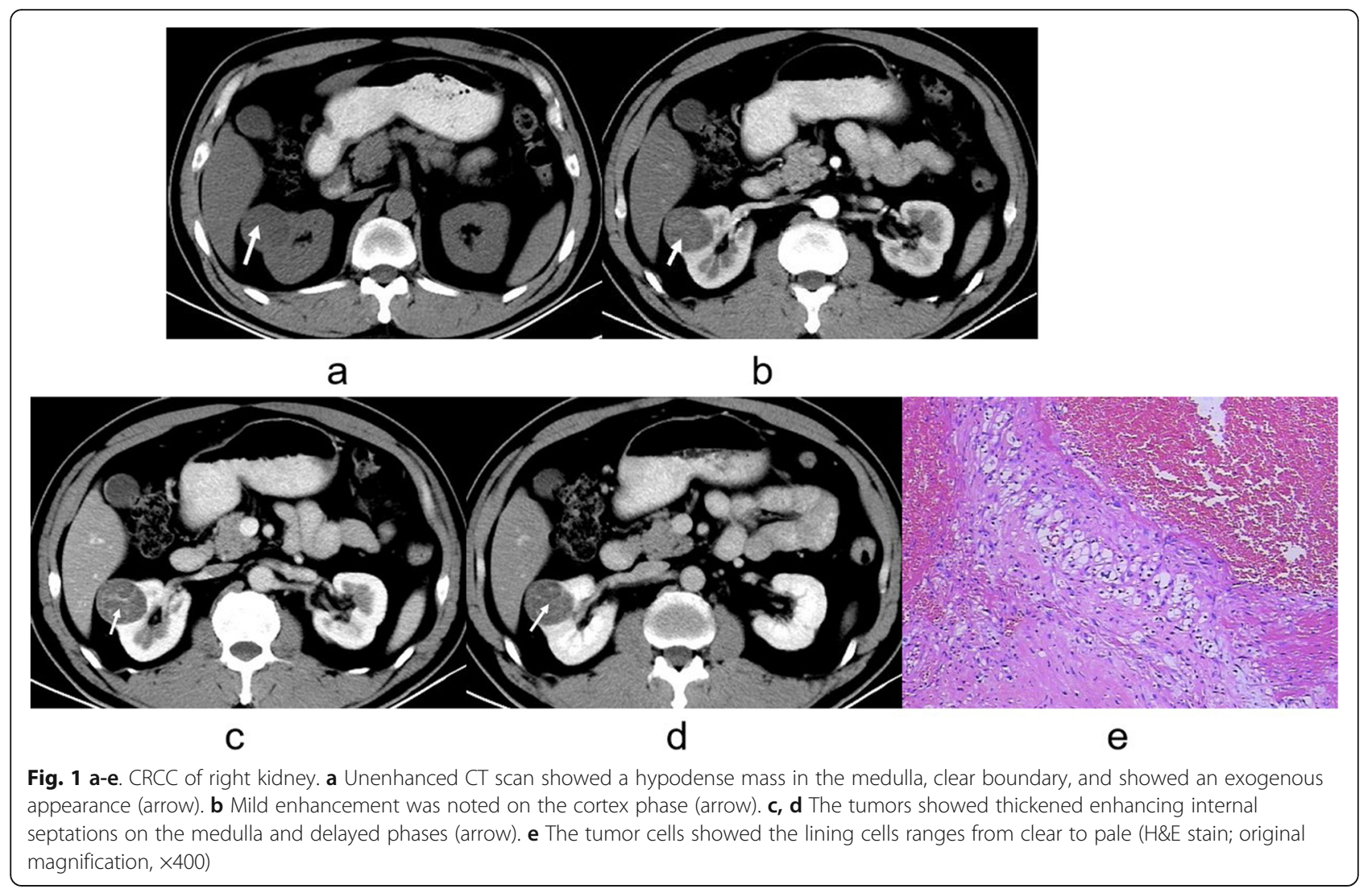

pathology studies, comparative study of CT appearances are scanty, particularly in combination with histopathologic examination. However, patients with CRCC have a better prognosis after undergoing total nephrectomy or local resection than that $\operatorname{CCDC}[9,10]$. So, an accurate diagnosis is important for guiding clinical treatment.

Histopathologycally, CCDC arise from the medulla as have been previously noted in the literatures, which distinguish them from the CRCCs that arise from the renal cortex [11]. Other tumors may also involve the renal medulla, e.g., transitional cell carcinoma [12], squamous cell carcinoma [13] and chromophobe renal cell carcinoma [14]. It is difficult to differentiate CCDC from other tumors if only relying on tumor position [15]. Other characteristics may be helpful, e.g., transitional cell carcinomas arise from the collecting system and may cause hydronephrosis [16]. Transitional cell carcinomas, also tend to involve the kidney by infiltration [17]. A centrally located CCDC with invasion into the renal pelvis may be indistinguishable from an invasive transitional cell carcinoma of the renal pelvis. This distinction, however, has important implications for treatment because nephroureterectomy is indicated for urothelial carcinomas, whereas nephrectomy is performed for renal parenchymal malignancies [18]. Chromophobe renal cell carcinomas may have a spoke-like pattern in some cases.
Our results show that 10 cases of CCDCs appear as heterogeneous hyper-attenuating tumors $(>45 \mathrm{HU})$, while all cases of CRCCs appear as hypodense masses. Other authors reported that the pathological basis for hyperdense appearance of a tumor on unenhanced CT was mainly minimal intratumoral hemorrhage (hemosiderin deposition) $[19,20]$. On pathology, we found 10 cases of CCDC whereas only one case of CRCC with intratumoral hemorrhage (hemosiderin deposition) $\quad(P<$ 0.0001).

In our study, 30 patients with CRCC and in 2 with CCDC the tumors had a clear boundary $(P<0.0001)$, which was best seen in the delayed phase. Infiltrative growth is a much more common pattern with CCDC where a WEs CRCC tumors grow by radial exogenous appearance [21]. Infiltrative lesions may enlarge the kidney but usually maintain the reniform contour. These growth patterns can often be distinguished on crosssectional imaging through analysis of tumor morphology [22]. As evident in our series, both infiltrative and exogenous patterns may coexist to various degrees.

In 31 patients with CRCC and in 2 with CCDC the tumors had thickened enhancing internal septations [23, 24]. Specific lesions that can look like CRCC or CCDC [25] include some hemorrhagic cysts, atypical cysts, cystic nephroma, and extensively CRCC [26]. Cystic 


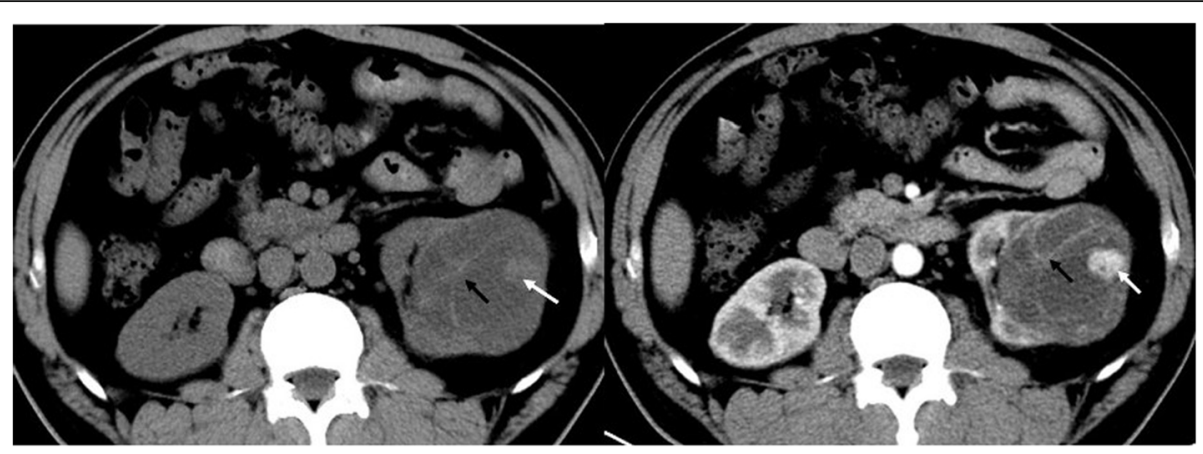

a

b

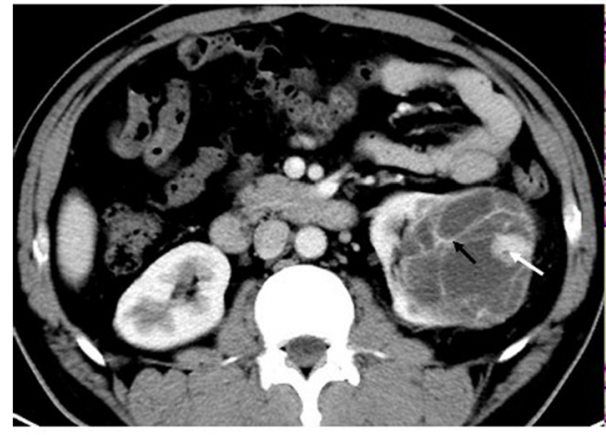

C

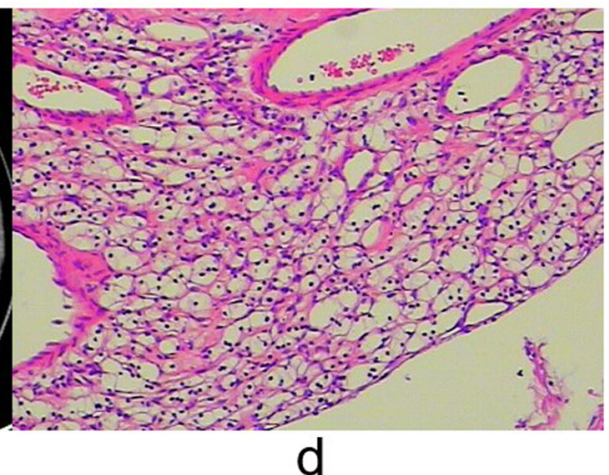

Fig. 2 a-d. CRCC of left kidney. a Unenhanced CT scan showed a hypodense mass in the medulla, clear boundary, and showed an exogenous appearance (arrow). b, c Obvious enhancement was noted with mural soft-tissue nodules (white arrow) together with thickened enhancing internal septations (black arrow) on the cortex and medulla phases. $\mathbf{d}$ The tumor cells showed the cytoplasm ranges from clear to pale. The septa consist of fibrous tissue, densely collagenous(H\&E stain; original magnification, $\times 400$ )

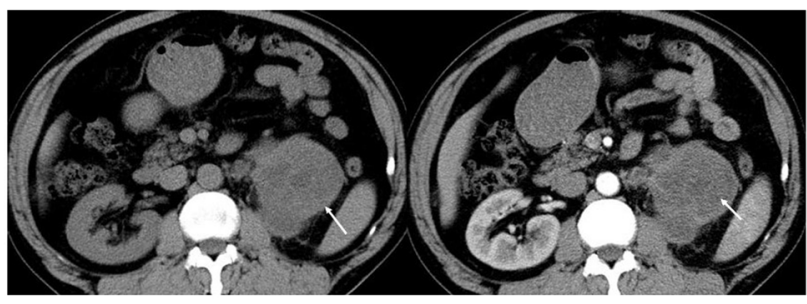

a

b
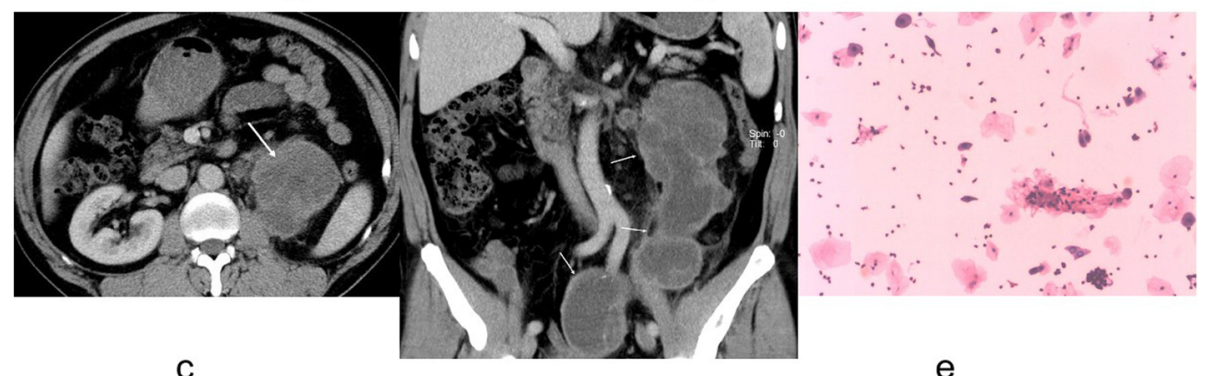

d

e

Fig. 3 a-e. CCDC of left kidney. a Unenhanced CT scan showed a hypodense mass in the medulla, unclear boundary, and showed an infiltrative appearance (arrow). b, c Mild, heterogeneous enhancement was noted on the cortex and medulla phases (arrow). $\mathbf{d}$ The tumors invaded the renal pelvis ureter (arrows). e The tumors cells were tubular and papillary growth pattern (H\&E stain; original magnification, $\times 400$ ) 

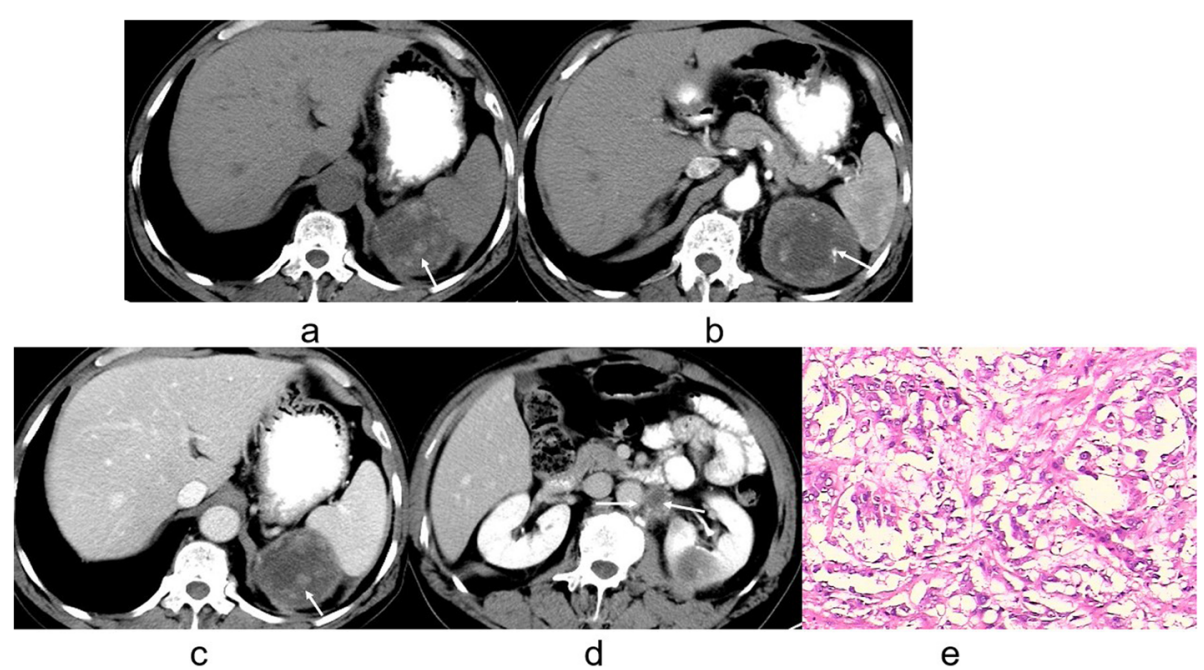

Fig. 4 a-e. CCDC of left kidney. a Unenhanced CT scan showed a heterogeneous mass together with hemorrhage and calcification (arrow). b, c Mild, heterogeneous enhancement was noted on the cortex and medulla phases (arrow). Tumors had an unclear boundary and showed an infiltrative appearance (arrow). d Tumors had retroperitoneal lymph node metastasis (arrow). e The tumor cells showed tubulopapillary, pseudopapillary, and cribriform patterns (H\&E stain; original magnification, $\times 400$ )

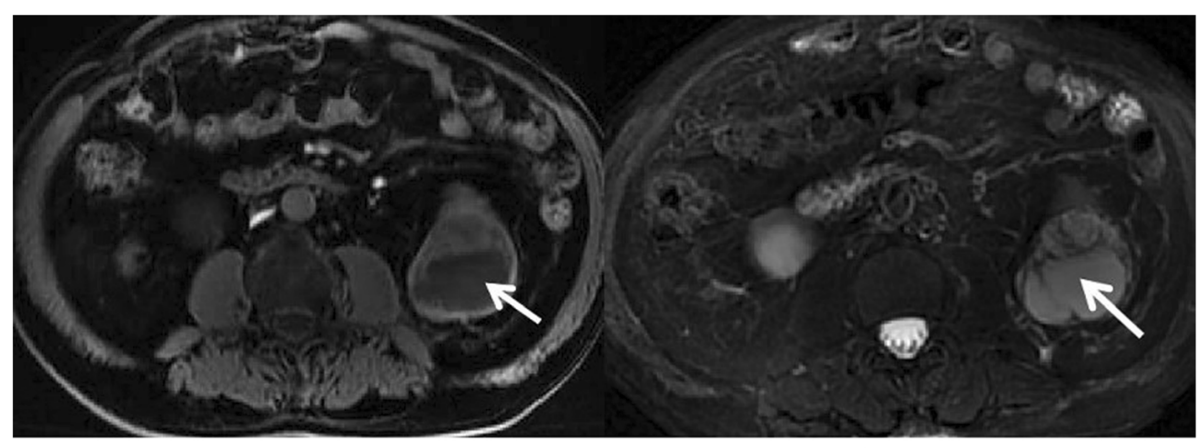

a

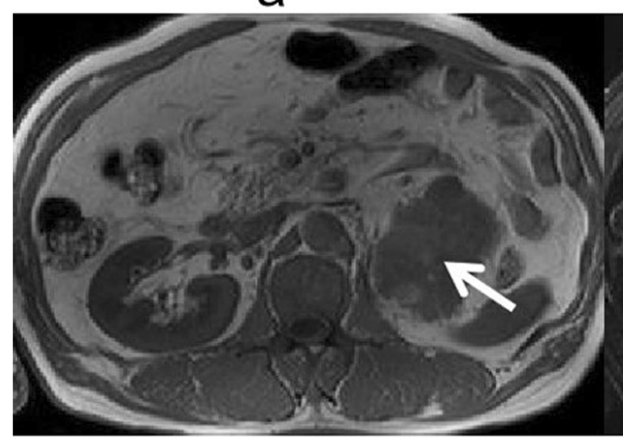

b

C

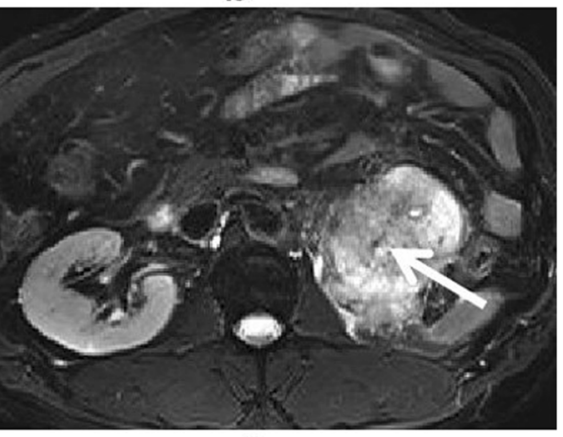

d

Fig. 5 a-d. CRCC and CCDC of MR imaging. a CRCC appeared hypointense on T1-weighted images. $\mathbf{b}$ CRCC appeared hyperintense on T2weighted images. c CCDC appeared hypointense on T1-weighted images. d CCDC appeared hypointense on T2-weighted images 
nephroma consists of a circumscribed mass of cysts with intervening fibrous septa, occasionally areas of calcification [27]. Unlike in multilocular CRCC, the cyst lining and septa do not exhibit evidence of clear cell proliferation [28].

In one patient with $\mathrm{CRCC}$ and in 10 with $\mathrm{CCDC}$ the tumors invaded the renal pelvis or ureter $(P<$ 0.0001). In 2 patients with CRCC and 10 patients with CCDC had retroperitoneal lymph node or distant metastasis $(P<0.0001)$. Hence the differential biological behavior of the tumors may also provide useful diagnostic information [29].

In the preoperative radiological work-up, MRI is the best modality for providing important information to diagnose RCC subtypes [30]. In our study, all CRCCs appeared hypointense on T1-weighted images and hyperintense on T2-weighted images, however, all CCDCs appeared hypointense on T1-weighted images and hypointense on T2-weighted images $(P<0.0001)$. In general, CRCC appears slightly hypointense to normal renal parenchyma on T1-weighted images and hyperintense on T2-weighted images. The CCDC was hypointense on T2-weighted images and did not have a hypointense rim. Along with MRI, hypointensity on T2-weighted images appears to favor CCDC, especially with a centrally located tumor.

Renal cell carcinoma, the most common neoplasm of the adult kidney accounts for $2-3 \%$ of all malignant diseases in adults. Although imaging techniques for abdominal screening have led to the increased incidental detection of renal tumor, unfortunately $25-30 \%$ patients still have metastases at presentation. Metastatic renal cell carcinoma is one of the most treatment resistant malignancies and patients have a dismal prognosis with $\mathrm{a}<10 \%$ 5-year survival rate. The identification of markers that can predict the potential of metastases will have a great impact in improving the patient's outcome. The described monoclonal antibody might be used as a research tool to assess bilitranslocase as a marker of transition from normal tissue to its neoplastic transformation in human kidney [31].

Information regarding the clinical behavior of these two tumors is limited due to its rare incidence. Among our 33 patients with CRCCs, they were alive without manifesting disease or any other signs or symptoms from 3 years to 10 years follow-up. However, 13 patients with CCDCs, 9 patients expired within 5 years of the initial diagnosis and the others are currently still alive. Although the clinical course of these patients is rather indolent, routine follow-up is still mandatory. The correct distinction of the tumors can lead to better understanding of their clinicopathologic differences, which should aid in developing individualized management plans.
Our study has several limitations. First, our study is limited by the relatively small number of patients with the two rare tumors. Further research is needed to verify our findings in larger patient populations. Second, only13 patients with CRCC and 4 patients with CCDC underwent MR examinations, so, the MR features of these two renal tumors need further investigation. Third, standardized definitions of imaging features of renal masses was not used. Fourth, the retrospective nature and single center of this study might have introduced some form of patient selection bias, therefore, prospective and multi-center studies are recommended.

\section{Conclusions}

In conclusion, distinguishing features of CRCC and CCDC included calcifications, capsule signs, infiltrative appearance, metastasis, internal septations, mural nodules and signal on CT or MR images. These imaging features may help in differentiating the two renal tumor types.

\section{Abbreviations}

CRCC: Cystic renal cell carcinoma; CCDC: cystic collecting duct carcinoma; MRI: Magnetic resonance imaging; ROI: Region of interest

\section{Acknowledgements}

N/A.

\section{Authors' contributions}

Guarantors of integrity of entire study, all authors; study concepts/study design or data acquisition or data analysis/interpretation, all authors; manuscript drafting or manuscript revision for important intellectual content, all authors; approval of final version of submitted manuscript, all authors; literature research, all authors; clinical studies, Qingqiang Zhu, Jun Ling, Jing Ye, Wenrong Zhu, Jingtao Wu.; statistical analysis, Qingqiang Zhu, Jing Ye, Wenrong Zhu; manuscript editing, all authors.

\section{Availability of data and materials}

The image dataset is available at the Medical Imaging, Clinical Medical College, Yangzhou University, Yangzhou, China.

\section{Declarations}

Ethics approval and consent to participate

This study was approved by the Institutional Research Ethics Committee.

Consent for publication

N/A.

Competing interests

The authors declare that they have no competing interests.

Received: 13 August 2020 Accepted: 29 July 2021

Published online: 07 September 2021

References

1. Song C, Min GE, Song K, Kim JK, Hong B, Kim CS, Ahn H. Differential diagnosis of complex cystic renal mass using multiphase computerized tomography. J Urol. 2009;181(6):2446-50.

2. Gong G, Lin T, Yuan Y, Li Y, Liu R. Bilateral kidneys involvement of collecting duct carcinoma with cystic change: A case report. Med (Baltim). 2019;98(4): e14236.

3. Kim M, Joo JW, Lee SJ, Cho YA, Park CK, Cho NH. Comprehensive Immunoprofiles of Renal Cell Carcinoma Subtypes. Cancers (Basel). 2020; 12(3):602. 
4. Sheir KZ, El-Azab M, Mosbah A, El-Baz M, Shaaban AA. Differentiation of renal cell carcinoma subtypes by multislice computerized tomography. Urol. 2005;174(2):451-5.

5. Bosniak MA. The current radiological approach to renal cysts. Radiology. 1986;158(1):1-10.

6. Israel GM, Bosniak MA. Follow-up $C T$ of moderately complex cystic lesions of the kidney (Bosniak category IIF). AJR Am J Roentgenol. 2003;181(3):62733.

7. Lam JS, Shvarts O, Said JW, Pantuck AJ, Seligson DB, Aldridge ME, Bui MH, Liu X, Horvath S, Figlin RA, et al. Clinicopathologic and molecular correlations of necrosis in the primary tumor of patients with renal cell carcinoma. Cancer. 2005;103(12):2517-25.

8. Agnello F, Albano D, Micci G, Di Buono G, Agrusa A, Salvaggio G, Pardo S, Sparacia G, Bartolotta TV, Midiri M, et al. CT and MR imaging of cystic renal lesions. Insights Imaging. 2020;11(1):5.

9. Sun M, Wang C, Jiang F, Fang X, Guo B. Diagnostic value and clinical significance of ultrasound combined with $C T$ in cystic renal cell carcinoma. Oncol Lett. 2019;18:1395-401.

10. Carrión López P, Martínez Ruiz J, Fernández Anguita PJ, Martínez Sanchiz C, Perán Teruel M, Atienzar Tobarra M. Virseda Rodríguez JA. Tubulocystic rena carcinoma (low grade collecting duct carcinoma). Arch Esp Urol. 2012;65(9): 841-4.

11. Radopoulos D, Dimitriadis G, Gologinas P, Tahmatzopoulos A, Kotakidou R. Solitary multilocular cystic renal cell carcinoma in adults: diagnostic problems, pathological features and treatment. Scand J Urol Nephrol. 2009; 43(1):84-7.

12. Lavallée LT, McAlpine K, Kapoor A, Pouliot F, Mason R, Violette PD, Bansal RK, Richard PO, Karakiewicz PI, Bhindi B, et al. Kidney Cancer Research Network of Canada (KCRNC) consensus statement on the role of renal mass biopsy in the management of kidney cancer. Can Urol Assoc J. 2019;13(12): 377-83.

13. Na KY, Kim HS, Park YK, Chang SG, Kim YW. Multifocal renal cell carcinoma of different histological subtypes in autosomal dominant polycystic kidney disease. Korean J Pathol. 2012;46(4):382-6.

14. Lee SH, Yoon SH, Nam JG, Kim HJ, Ahn SY, Kim HK, Lee HJ, Lee HH, Cheon GJ, Goo JM. Distinguishing between Thymic Epithelial Tumors and Benign Cysts via Computed Tomography. Korean J Radiol. 2019;20(4):671-82.

15. Nason GJ, McGuire BB, Kelly ME, Murphy TM, Looney AT, Byrne DP, Mulvin DW, Galvin DJ, Quinlan DM, Lennon GM. Clinico-pathological analysis of renal cell carcinoma demonstrates decreasing tumour grade over a 17-year period. Can Urol Assoc J. 2014;8(3-4):125-32.

16. Yu C, Li T, Zhang R, Yang X, Yang Z, Xin L, Zhao Z. Dual-energy CT perfusion imaging for differentiating WHO subtypes of thymic epithelial tumors. Sci Rep. 2020;10(1):5511.

17. Barrascout E, Beuselinck B, Ayllon J, Bättig B, Moch H, Teghom C, Oudard S. Complete remission of pulmonary metastases of Bellini duct carcinoma with cisplatin, gemcitabine and bevacizumab. Am J Case Rep. 2012;13:1-2

18. Stamatiou KN, Sofras F. Multilocular cystic nephroma and multicystic clear cell carcinoma: two faces of the Roman god Janus? Int J Surg Pathol. 2009; 17(2):170-1.

19. Yoon SK, Nam KJ, Rha SH, Kim JK, Cho KS, Kim B, Kim KH, Kim KA. Collecting duct carcinoma of the kidney: CT and pathologic correlation. Eur J Radiol. 2006 Mar;57(3):453-60

20. Gong K, Zhang N, He Z, Zhou L, Lin G, Na Y. Multilocular cystic renal cell carcinoma: an experience of clinical management for 31 cases. J Cancer Res Clin Oncol. 2008;134(4):433-7.

21. Nagano N, Ishikawa N, Nagase M, Fukushima T, Shiina H, Maruyama R. A case report of unilocular cystic mucinous tubular and spindle cell carcinoma with mural tumor nodule. Urol Case Rep. 2019;27:101007.

22. Pickhardt PJ, Siegel CL, McLarney JK. Collecting duct carcinoma of the kidney: are imaging findings suggestive of the diagnosis? AJR Am J Roentgenol. 2001;176(3):627-33.

23. McDaid J, Farkash EA, Steele DJ, Martins PN, Kotton CN, Elias N, Ko DS Colvin RB, Hertl M. Transitional cell carcinoma arising within a pediatric donor renal transplant in association with BK nephropathy. Transplantation. 2013;95(5):e28-30

24. Silverman SG, Mortele KJ, Tuncali K, Jinzaki M, Cibas ES. Hyperattenuating renal masses: etiologies, pathogenesis, and imaging evaluation. Radiographics. 2007;27(4):1131-43.

25. Bose D, Das RN, Chatterjee U, Banerjee U. Collecting duct carcinoma: A rare malignancy. J Cancer Res Ther. 2013;9(1):94-5.
26. O'Malley RL, Godoy G, Hecht EM, Stifelman MD, Taneja SS. Bosniak category IIF designation and surgery for complex renal cysts. J Urol. 2009;182(3): 1091-5.

27. Hindman NM, Bosniak MA, Rosenkrantz AB, Lee-Felker S, Melamed J. Multilocular cystic renal cell carcinoma: comparison of imaging and pathologic findings. AJR Am J Roentgenol. 2012;198(1):W20-6.

28. Alexiev BA, Thomas C, Zou YS. Clear cell papillary renal cell carcinoma with angiomyomatous stroma: a histological, immunohistochemical, and fluorescence in situ hybridization study. Virchows Arch. 2014;464(6):709-16.

29. El Khoury J, Abdessater M, Halabi R, Nasr F, Boustany J, Kanbar A, El Hachem C. El Khoury R. Bellini Duct Carcinoma Misdiagnosed with Urothelial Papillary Carcinoma. Case Rep Oncol Med. 2020;2020:3174674.

30. Gurel S, Narra V, Elsayes KM, Siegel CL, Chen ZE, Brown JJ. Subtypes of renal cell carcinoma: MRI and pathological features. Diagn Interv Radiol. 2013; 19(4):304-11.

31. Montanic S, Terdoslavich M, Rajcevic U, De Leo L, Bonin S, Serbec VC, Passamonti S. Development and characterization of a novel mAb against bilitranslocase-a new biomarker of renal carcinoma. Radiol Oncol. 2013;47(2): 128-37.

\section{Publisher's Note}

Springer Nature remains neutral with regard to jurisdictional claims in published maps and institutional affiliations.
Ready to submit your research? Choose BMC and benefit from:

- fast, convenient online submission

- thorough peer review by experienced researchers in your field

- rapid publication on acceptance

- support for research data, including large and complex data types

- gold Open Access which fosters wider collaboration and increased citations

- maximum visibility for your research: over $100 \mathrm{M}$ website views per year

At BMC, research is always in progress.

Learn more biomedcentral.com/submissions 